\title{
A Controls Laboratory Program with an Accent on System Identification
}

\author{
Brian Armstrong \\ Department of Electrical Engineering and Computer Science, \\ University of Wisconsin - Milwaukee, \\ P.O. 784, Milwaukee, Wisconsin 53201, U.S.A. \\ bsra@ee.uwm.edu
}

\begin{abstract}
A sequence of laboratories is presented which have been designed to maximize student involvement in the design as well as execution of the laboratory exercises. The student works quite independently, starting with the simplest plant and control model, and a relatively structured identification experiment, controller design and performance assessment. The student moves to self-designed system identification and controller design. The cap stone of the course is a competitive controls application which challenges the students command of the theoretical tools as well as thoroughness and accuracy of experimental technique.
\end{abstract}

\section{Introduction}

The education literature provides many examples of high quality laboratory instruction programs in controls engineering (e.g. $[1,2,4]$ ). One challenge to designing any laboratory program is to involve the student in discovery learning, as opposed to closely directed verification of physical principles. The education literature makes clear that student involvement in the design as well as implementation of a laboratory exercise is an important contributor to two-year retention of the concepts presented [3].

The controls laboratory sequence presented here has been designed to meet the challenge of incorporating discovery learning. The laboratory sequence evolved incrementally over a period of four years during which time it gradually became clear that system identification could be used as a vehicle for increasing the students participation in the discovery process. In our first efforts, complete models were given the student and multi-term controllers were tested from the outset. Today, the student starts with a blank sheet of paper and each controller is designed by the student based on a model he or she has identified.

The semester culminates in a master-slave servo tracking problem in which the student implements control for a servo which must track a progressively more agile target. The final project is competitive, in the sense that each group's time to loss-of-target is measured, and corresponds to high-bandwidth performance of the engineered control.

The laboratory sequence is used in the Electrical Engineering program at the University of Wisconsin - Milwaukee with the first course in controls. This is an elective course usually taken by Electrical Engineering majors in the senior year. The course syllabus covers the traditional collection of topics, starting with Laplace transform and modelling, and concluding with design using root locus. 


\section{The Laboratory Sequence}

The laboratory sequence comprises five laboratory exercises which are outlined in table 1. The apparatus is a servo unit with DC motor and a potentiometer for position sensing. The electrical layout is illustrated in figure 1. During the first three labs, velocity is the control variable. Velocity is servoed to achieve a type- 0 system, so that open-loop and one-term (proportional only) control can be done. In labs 4 and 5, position is the control variable.

\begin{tabular}{|c|c|c|c|c|}
\hline $\begin{array}{c}\mathrm{Lab} \\
\#\end{array}$ & Identification & $\begin{array}{l}\text { Controller } \\
\text { Design }\end{array}$ & Measurements & Additional Topics \\
\hline $\begin{array}{l}1 \\
\& \\
2\end{array}$ & $\begin{array}{l}\text { DC Gain, } \\
\text { Velocity Servo }\end{array}$ & $\begin{array}{l}\text { Open-Loop and } \\
\text { P-type, } \\
\text { Closed-Loop }\end{array}$ & $\begin{array}{l}\text { Test: } \\
\text { Step Response, } \\
\text { Disturbance Rejection, } \\
\text { Parameter Variation }\end{array}$ & $\begin{array}{l}* \text { Linearization } \\
* \text { Loop Gain } \\
* \text { Uncertainty }\end{array}$ \\
\hline 3 & $\begin{array}{l}\text { Step Response, } \\
\text { 1st Order Model } \\
\text { Velocity Servo } \\
\end{array}$ & $\begin{array}{l}\text { PI by Pole- } \\
\text { Placement }\end{array}$ & $\begin{array}{l}\text { Test: } \\
\text { Step Response } \\
\text { Sinusoid Tracking }\end{array}$ & $\begin{array}{l}\text { * Model order and } \\
\text { Modelling } \\
\text { Accuracy } \\
* \text { Uncertainty } \\
\end{array}$ \\
\hline 4 & $\begin{array}{l}\text { Step Response, } \\
\text { Freq. Response } \\
\text { 2nd Order Model } \\
\text { Position Servo }\end{array}$ & $\mathrm{PD}$ and PID & $\begin{array}{l}\text { Ident. Experiments, } \\
\text { Step Resp. (Cl Lp) } \\
\text { Freq. Resp. (Opn Lp) } \\
\text { Tracking Error Meas. } \\
\text { (PD and PlD control) }\end{array}$ & $\begin{array}{l}* \text { Student Designed } \\
\text { Identification Exp. } \\
* \text { Uncertainty } \\
\text { Analysis } \\
\quad \text { for Nonlin. Syt. }\end{array}$ \\
\hline & $\begin{array}{l}\text { 4nd Order Model } \\
\text { om Freq. Resp. } \\
\text { Data }\end{array}$ & $\begin{array}{l}\text { PID Design by } \\
\text { Root Locus }\end{array}$ & $\begin{array}{l}\text { Competitive Target } \\
\text { Tracking }\end{array}$ & $\begin{array}{l}* \text { Root Locus Design } \\
* \text { Tuning }\end{array}$ \\
\hline
\end{tabular}

Table 1. Content of Labs 1-5.

\subsection{The first and second labs, zeroth order modelling and control}

As seen in table 1, the objective from the outset is that the student carry out non-trivial design with a complete system. This objective is approached by starting with the simplest possible system model: a DC gain; and the simplest possible controllers: open-loop (offset and proportional terms) and P-type closed-loop control, designed to meet a loop-gain specification. Nonetheless, the exercise involves identifying the DC gain, designing control, and measuring, comparing and contrasting controller performance. To prepare the student, the prelab must introduce several topics:

Topics of Prelab 1:

a. Introduction to the servo hardware and software.

b. Determining DC gain and designing open-loop control.

c. Designing P-type closed-loop control.

d. Designing P-type closed-loop control with feed forward. 


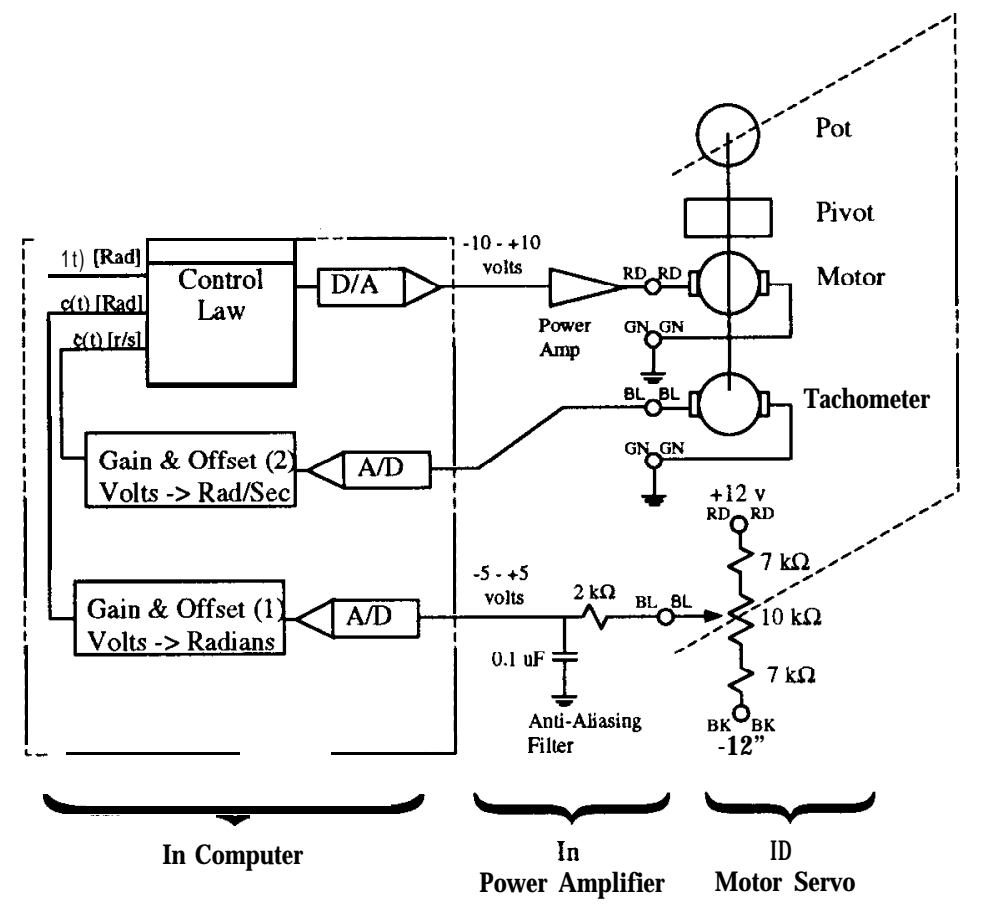

Figure 1. Electrical layout of the motor servo used in all 5 laboratory exercises.

e. Determining measures of the system response: steady state error.

f. Uncertainty estimation for measured values.

Topics of Prelab 2:

a. Developing and manipulating transfer functions.

b. Designing P-type closed-loop control for specified loop gain.

c. Determining measures of the system response:

- Rise time,

- Steady state error,

- Amplitude of a sinusoidal response.

d. Uncertainty estimation for computed values.

\section{1.a Lab 1 Activities}

The DC gain of the plant [velocity per volt] is obtained by applying several values of constant voltage and measuring the velocity. A two-term model is developed by linearizing about a specified operating point. This model is used to design a two-term open-loop controller giving unity gain and a P-type closed-loop controller giving loop gain of 10. Applying these controllers separately and combining them for closed-loop with feed-forward control, the students measure steady-state error during velocity regulation.

Standard uncertainty analysis techniques are used to estimate experimental uncertainty in the determination of model parameters.

\section{1.b Lab 2 Activities}

The first activity of the student in laboratory 2 is to develop the laboratory procedure itself, which is prepared from a description of the laboratory objectives. The students investigate the 
correlation between loop gain and rise time, steady-state error and peak motor command, as well as sensitivity to parameter variation and torque disturbance.

Parameter variation is introduce by increasing the series armature resistance of the servo motor from 6.4 to $16.4 \Omega$. A disturbance torque is introduce by laying the motor servo on its side, as seen in figure 2 .

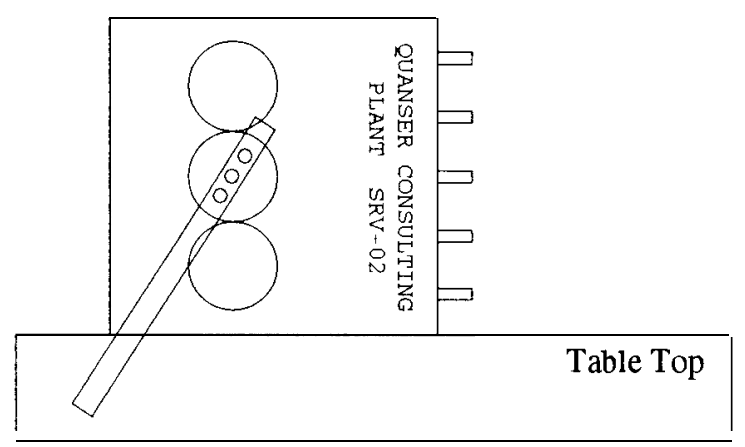

Figure 2. SRV-02 on its side, so that gravity provides a torque disturbance.

\subsection{The third lab, first order model identification}

As with the first and second, the third laboratory opens with a focus on system identification. Model complexity and performance objectives are extended by moving to a first order plant model and PI-type control. The topic of model complexity as a designer choice is introduced.

In lab, the first-order model is identified from open-loop step-response characteristics of rise time and transient amplitude. These measurements are distinct from those of laboratory 1, where the system is identified using steady-state velocity. Series-PI compensation leads to a 2nd order system with two controller parameters and Pole-placement design is used. The limits of the 1st order model are explored. The controller structure, also used for closed-loop control in labs 1 and 2 , is shown in figure 3 .

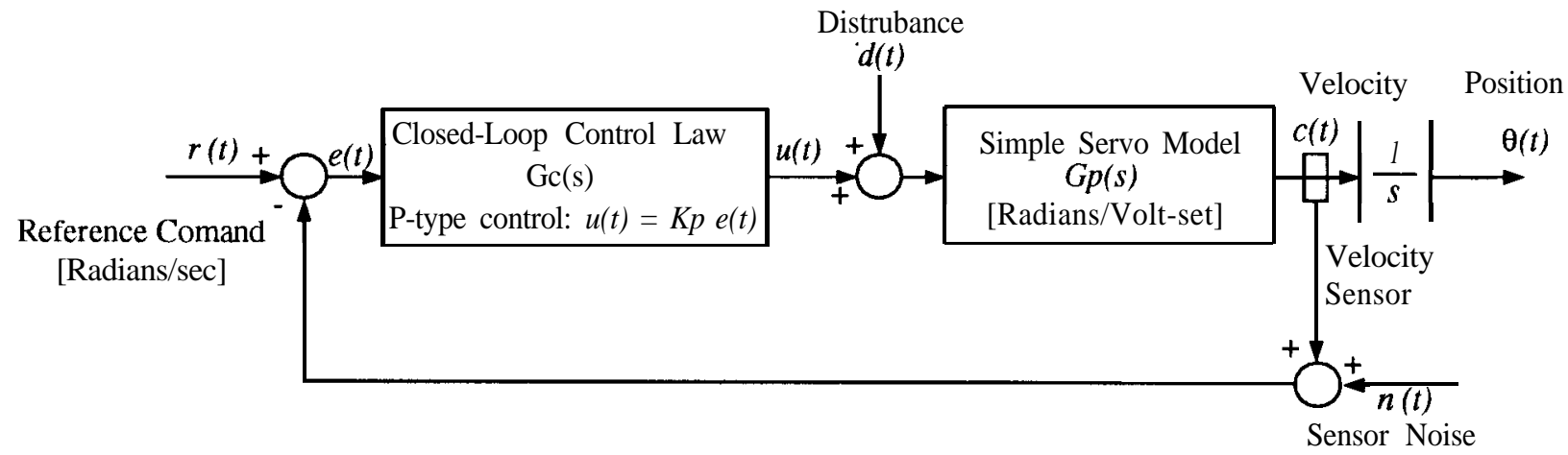

Figure 3. Closed-loop velocity control with position sensing, velocity estimation and disturbance input.

Responses to sinusoidal inputs are also explored in laboratory 3, to prepare the students to design an experiment for system identification from frequency response in laboratory 4. 


\subsection{The fourth lab, second order model identification, student-designed experiments}

With the 4th lab, use shifts from the type-O, velocity-controlled system to a type-1 positioncontrolled system. By this point in the semester, the analysis tools are available to understand the implications of a pole at the origin as well as the dynamics of a second order system.

During the prelab, a model identification procedure based on step response (from peak time and percent overshoot) is introduced, as well as identification from frequency response data using the MATLAB function invfreqs. The later method has the advantage of extensibility to a $4^{\text {th }}$ order model which captures a flexible mode that is important for achieving maximum closed-loop tracking performance.

In prelab 4, the students are tasked:

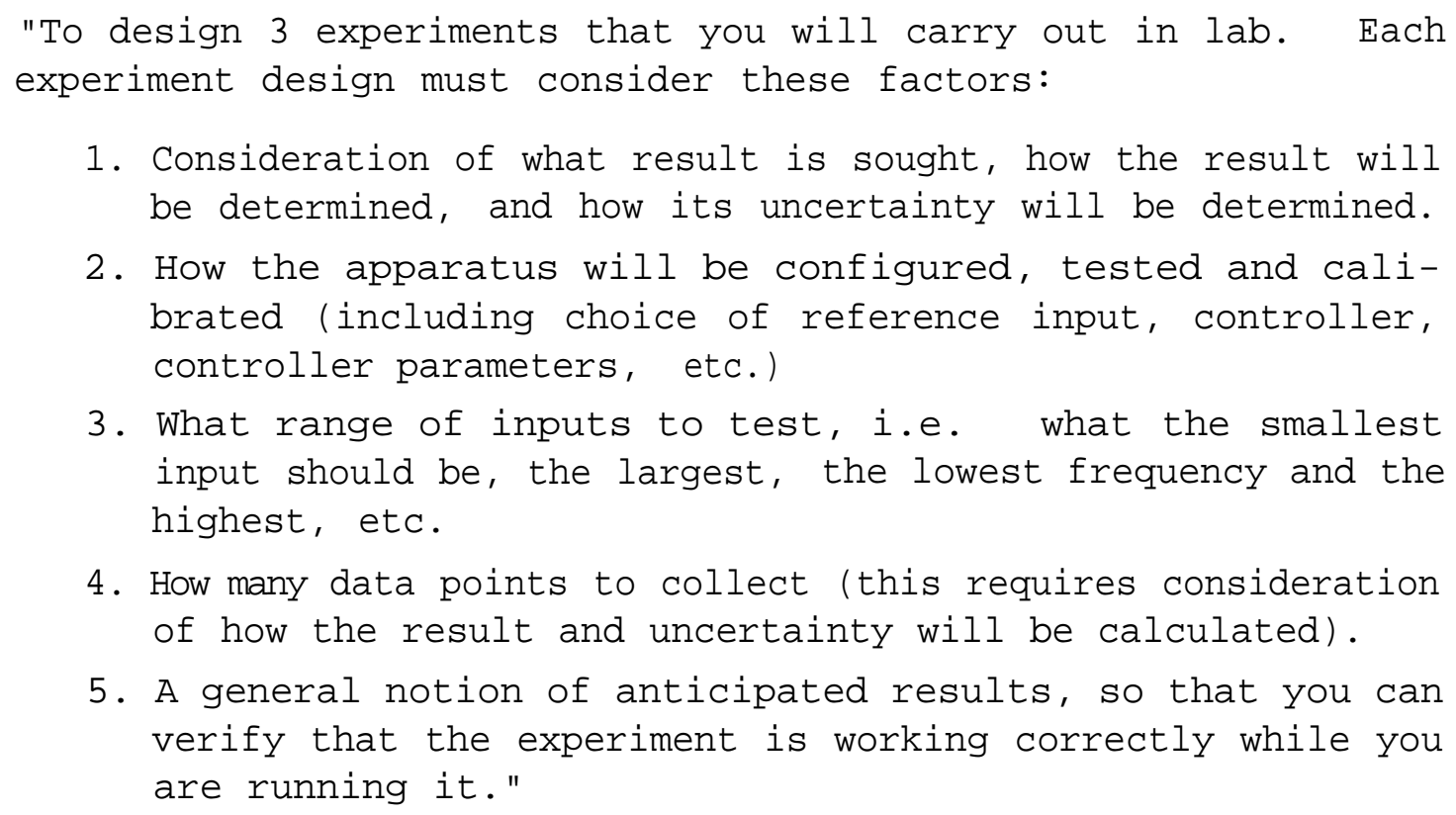

The students design three identification experiments: two directed toward plant transfer functions, and the third toward error transfer function. They must draw on their experience identifying one- and two-parameter models for the plant, as well as operating the servo hardware and software. Their experiment designs - as distinct from their results in the laboratory - are critically graded with respect to items 1-5, above.

The format for the laboratory report is quite open:

\footnotetext{
"Think of your laboratory report as a project report that you are writing as a consultant-subcontractor to a company with a major prime contract. Your report should be concise, and yet sufficiently complete to be useful. It should include:

1. A short abstract, describing what parameter was observed, how it was measured and summarizing the measurement.

2. A description of the measurement setup that is sufficiently complete that the measurement could be reproduced;
} 


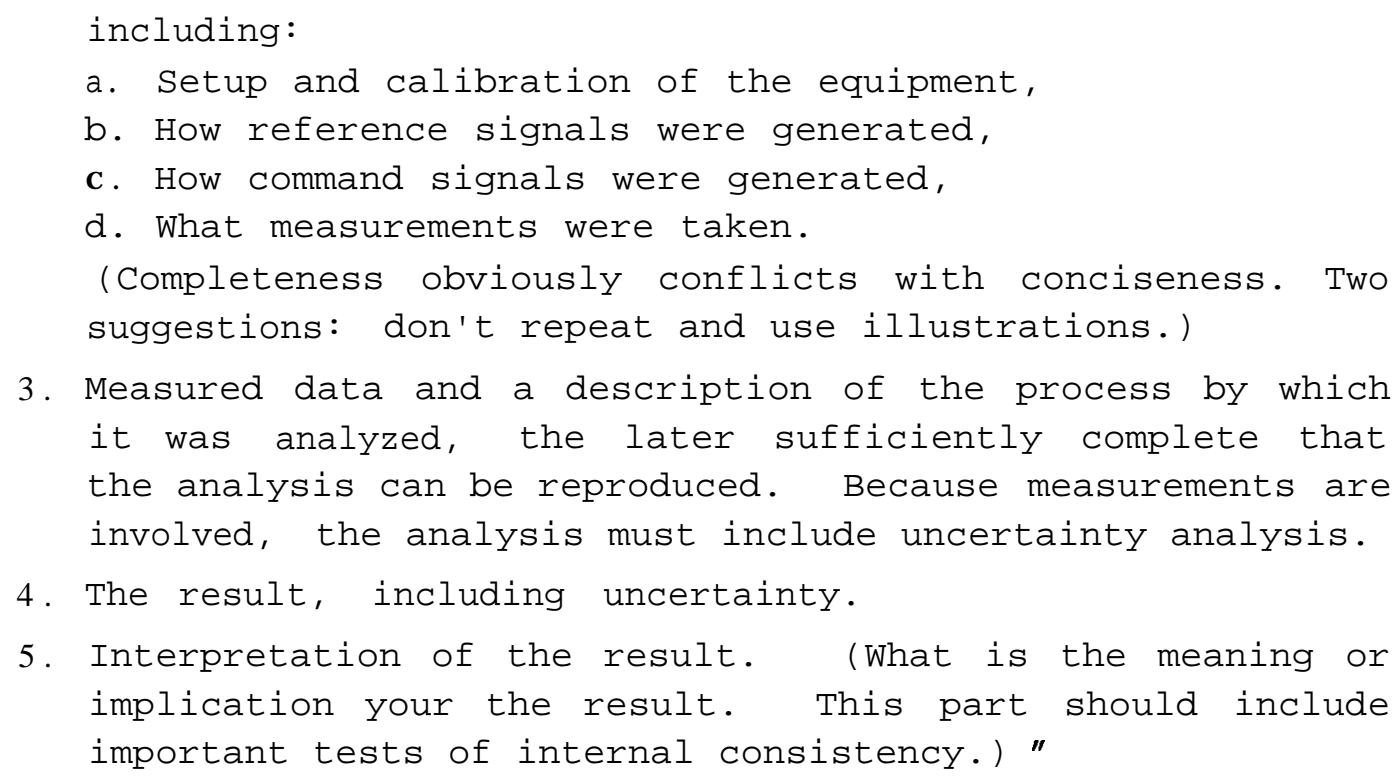

\subsection{The fifth lab: Staying on target}

In the fifth and final lab, the student is tasked to design a high-bandwidth PID positioncontroller for the motor servo. He or she will bring to bear on this task root-locus design techniques as well as simulation using the signals similar to those being tracked.

The apparatus is configured as shown in figures 4 and 5. As seen in figure 4, the output shafts of two SRV-02 motor servo units are connected by a wire link. The link slides in a groove in the block on the target unit, and rotates in a bushing on the tracker unit. As the target moves, the tracker must follow to keep the wire in the groove. The block and groove are $2 \mathrm{~cm}$ wide, allowing $+/-1 \mathrm{~cm}$ of motion error before the wire will fall out. The motion command to the target progressively increases in speed, and the challenge is to keep the tracker on the target (the wire in the groove) as long as possible. Performance is measured with a stop watch.

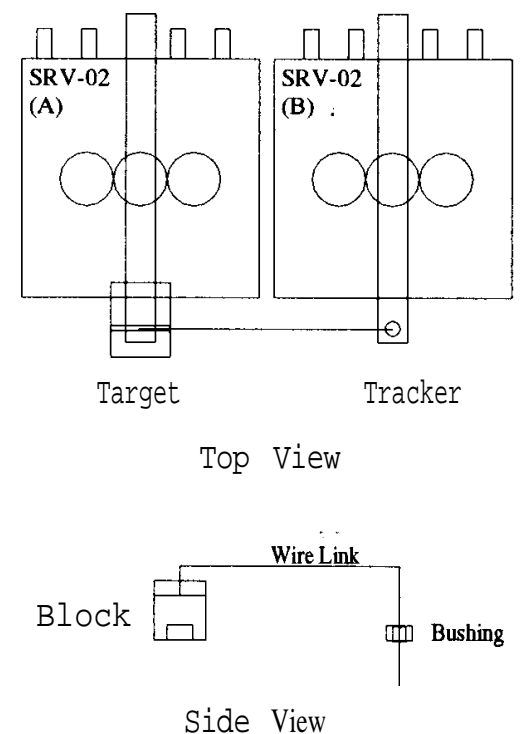

Figure 4. Mechanical configuration of the Tracker Tester. 

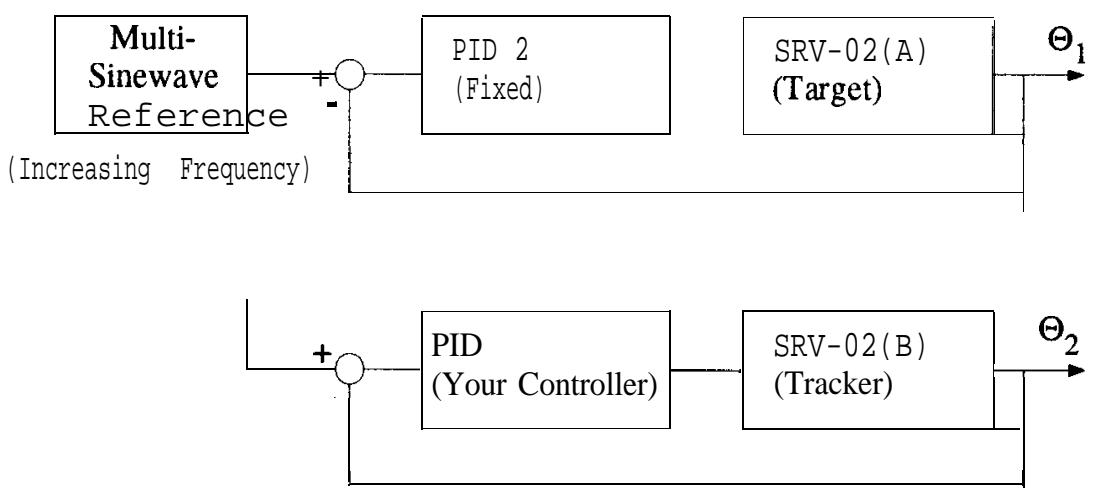

Figure 5. Signal connections of the Tracker Tester.

Each student group achieves two performance results: the performance of their first controller, designed before lab using the model identified with data from laboratory 4 and root locus and simulation techniques, and the performance of a controller tuned in lab. In part to balance the extensive reporting required in laboratory 4 , and in part to reduce the heat at the end of the semester, the reporting requirement is modest:

"Write a short report (1 page maximum, not including figures)

describing the most important aspects of how you arrived at your

controller design."

\section{Facilities}

These laboratory exercises are carried out with motor servo hardware built by Quanser Consulting, Toronto, Canada; Keithley-Metrabyte DAS 1602 A/D and D/A cards; and a custom C language controller which implements a menu driven system for selecting events and controllers, capturing data, etc.

\section{Conclusion}

A sequence of laboratories is presented which have been designed with the goal of maximizing student involvement in the design as well as execution of the laboratory exercises. While an element of verifying the results of lecture-presented analysis remains, the main thrust of the laboratory sequence is student involvement in student-designed laboratory exercises. The student works quite independently, starting with the simplest plant and control model, and a relatively structured identification experiment, controller design and performance assessment. The student moves to self-designed identification experiments and controller design. The cap stone of the course is a competitive controls application which challenges the student's command of the theoretical tools as well as thoroughness and accuracy of experimental technique.

\section{Acknowledgments}

Thanks go to Keithley-Metrabyte and Hewlett Packard, for donating equipment to the controls laboratory at UWM; and to Jacob Apkarian, Quansar Consulting, Inc. for patiently working with us as the design for the SRV-02 evolved. Notebook ${ }^{\mathrm{TM}}$ is a trademark of Keithley MetraByte. 


\section{Bibliography}

[1] Stephen Yurkovich (Ed.). Special issues on advances in control education. IEEE Control Systems Magazine, 12(3), 1992.

[2] R. Russell Rhinehart. An integrated process control laboratory. In Proc. 1994 American Control Conference, pages 378-82. AACC: Baltimore, 1994.

[3] B. Rosenshine. Synthesis of research on explicit teaching. Educational Leadership, 73(7):60-69, 1986.

[4] Stephen Yurkovich. The instructional control laboratories in electrical engineering at the ohio state university. In Proc. 1993 A merican Control Conference, pages 2014-17. AACC: San Francisco, 1993.

\section{Author's Biography}

Brian Armstrong received B.Sc. degrees in Physics and Mechanical Engineering from MIT in 1980, and the M.Sc. and Ph.D. degrees in Electrical Engineering from Stanford University in 1984 and 1988. He joined the Electrical Engineering and Computer Science faculty of the University of Wisconsin - Milwaukee as an Assistant Professor in 1989 and became an Associate Professor in 1995. In 1986, 1988 and 1991 he held visiting positions with Mitsubishi Electric Company, Osaka, Japan; INRIA, then in Rennes, France; and the State University of Campinas, Campinas Brazil. His interests include problems of identification and control in robotics and other nonlinear systems. 